\title{
Pediatric ocular trauma: A prospective cohort study on the globe rupture subgroup of open globe injuries
}

\author{
Mehul Shah ${ }^{1 *}$, Shreya Shah ${ }^{1}$, Pradeep handana ${ }^{1}$, Ashvini Korane ${ }^{1}$ and Deeksha Thorat $^{1}$ \\ ${ }^{1}$ Medical Director Retina, Dahod, Gujarat, India
}

*Corresponding author: Mehul Shah, Drashti Netralaya, Nr GIDC, Chakalia Road, Dahod-389151, Gujarat, India.

Received Date: July 09, 2021

Published Date: August 02, 2021

\begin{abstract}
Purpose: This work attempts to investigate the clinical profile as well as consequences of globe rupture, which constitutes a key subclass of open globe ocular trauma, in pediatric patients as per the Birmingham Eye Trauma Terminology System.

Methods: All pediatric ocular trauma patients with mechanical eye injury who were enrolled at the ocular trauma care center between 2007 and 2019 were included in this prospective cohort study. All anterior and posterior segment findings on presentation, during surgical procedure and follow up were documented. The international ocular trauma society form was employed to acquire the data through our online MIS, and the details were exported to Excel sheet. The data were statistically analyzed by performing univariate analysis and cross tabulation with the help of SPSS 22 software.
\end{abstract}

Results: Among the 12687 patients with mechanical ocular trauma, 7546 (59.4\%) had endured open globe injuries while 5328 (41.9\%) had sustained closed globe injuries. In the former, $818(10.8 \%)$ fell under the globe rupture category and $417(51 \%)$ belonged to the pediatric age group $(0-18$ years). The mean age of the patients was $8.4 \pm 4.5$ years; 283 were males $(67.9 \%)$ and 134 were females $(32.1 \%)$. The mean size of the wound was $6.18 \mathrm{~mm}$. Comparative studies between the pre- and post-treatment data indicated a significant difference in the visual outcome. Out of all, 18 (4.3\%) eyes presented with infection.

Conclusion: Based on our findings, it could be inferred that globe rupture subcategory of open globe injury is a important cause of vision loss in the pediatric age group $(45.1 \%<1 / 60)$, with the problem being more widespread among the males $(>67.2 \%)$ than females. The therapeutic approach encompasses multiple surgeries and is beneficial in improving the vision of the young patients.

Keywords: Birmingham Eye Trauma Terminology System; Open Globe Injuries; Globe Rupture Trauma; Pediatric Ocular Trauma

\section{Introduction}

Even though certain researchers have focused on ocular trauma in rural areas, the issue is more prevalent in the urban setting and happens to be an important cause of monocular blindness [1]. It is necessary to build a sound epidemiological database and develop a good understanding of the causes/outcomes of injury to devise appropriate strategies for preventing them. The etiology of ocular injury differs markedly between the urban and rural areas and needs to be examined closely [2-4]. As eye injuries pose a large, potentially preventable burden to the victim and the society at large, we need to channelize our resources to prevent such injuries and alleviate the burden [3]. Damage to the surrounding ocular tissues may compromise the visual gain after surgery for managing the traumatic cataracts, thereby decreasing the success rate when compared with eyes having non-traumatic cataracts. Traumatic cataracts are often associated with poor visual outcomes in children because of the amblyopia and recurrent inflammation. In pediatric population, the possibility of amblyopia has to be considered as strabismus, refractive errors, or ocular opacity can result in the condition [5].

The use of Birmingham Eye Trauma Terminology System (BETTS) has standardized the definition of ocular trauma [5], making it possible to compare the visual outcomes following traumatic cataract surgery and understand the determinants in predicting the outcomes. Various studies have reported the visual 
outcomes of ocular trauma; however, most were case studies or involved only a small sample size [6-8]. Globe rupture is a subgroup of open globe injury with poor prognosis as there are many determinants which influence the outcome. The objective of this study is to determine the clinical profile and visual outcome of the globe rupture subcategory of ocular trauma. Our research was conducted in a city located along the borders of three Indian states, namely Gujarat, Madhya Pradesh, and Rajasthan. Qualified ophthalmologists of our institute provide low-cost eye services primarily to the 5.3 million poor tribal people residing in the area.

\section{Key Messages:}

What was known: Globe rupture subcategory of open globe injury can cause severe sight loss

\section{What is new}

1. This is analysis of one of very large database of Globe Rupture in pediatric age group.

2. Despite of significant improvement in vision following management severe sight loss is inevitable- $45 \%$ eyes did not regain more than $1 / 60$

3. Significant improvement in visual outcome in zone 1 injuries as compared to zone 3 injuries

4. Size and shape of wound did not influence but required number of surgeries influenced outcome.

\section{Materials and Methods}

This was a prospective cohort study conducted at a tertiary referral eye care hospital in Western India. Institutional ethical approval with informed consent was obtained for this research. All children aged 18 and under who had experienced mechanical ocular trauma and had been examined and received surgical treatment between January 2007 and December 2019 were enrolled. The globe rupture subgroup of open globe injury data was analyzed. Globe rupture was defined according to BETTS full thickness wound caused by blunt object(ref) All details regarding anterior and posterior segment documented in online format of electronic medical record. Data regarding both the initial and follow-up reports were collected using the online World Eye Injury Registry form [5-7]. The data collected online included demographics of the patient, including history of the injury and details of the treatment received. Information on the surgery was also gathered using a specific pretested online form. Demographic details such as patient characteristics, activity at the time of injury, cause of injury, and details of the ocular examination and treatment were entered in a pretested datasheet. Visual acuity was reported according to age based on the guidelines issued by the American Association of Pediatric Ophthalmology. (AAPOS) [9]. The cases were initially divided into two groups using BETTS, namely open globe, and closed globe injury. The former was further subcategorized into laceration and rupture groups. Lacerations of the eyeball were in turn grouped into perforating injury, penetrating injury, and injury involving an intraocular foreign body. Specific data related to the number of zones of injury, size of wound, number of surgeries performed, and presence or absence of infection were obtained. In patients with open globe injury, a two-step surgical approach was adopted, and the traumatic cataract was operated at the second sitting. Further management was done according to the anterior or posterior segment findings. Posterior segment management depended on the comorbidities found. When the ocular medium appeared hazy due to inflammation of the anterior vitreous, capsulectomy and vitrectomy were performed via the anterior/ pars plana route $[10,11]$. In children younger than 2 years of age, both lensectomy and vitrectomy via the pars plana route were performed, leaving a rim of the anterior capsule for the secondary implant. The same surgical procedures were used to manage the traumatic cataract. Lens implantation as part of the primary procedure was avoided in all children younger than 2 years of age. Such patients were rehabilitated with optical correction, and a secondary implant was performed after 2 years. All the cases were examined by a qualified pediatric orthoptist for supportive amblyopia therapy. All injured patients who were uninfected were treated by administering topical and systemic corticosteroids and cycloplegics. The duration depended on the degree of inflammation in the anterior and posterior segments of the operated eye. The operated patients were re-examined after $24 \mathrm{~h}, 3$ days, and 1, 2, and 6 weeks to enable refractive correction. Follow-up was scheduled for post-op day 3, and the frequency was weekly for 6 weeks, monthly for 3 months, and then every 3 months for 1 year. At every follow-up, visual acuity was tested according to age as per the AAPOS guidelines [12]. The anterior segment was examined with a slit lamp, and the posterior segment was checked with an indirect ophthalmoscope. All these data exported from electronic medical records to excel sheet. The Statistical Package for Social Studies (SPSS 22) was used to analyze the data. The univariate parametric method was employed to calculate the frequency, percentage, proportion, and 95\% confidence interval (95\% CI).

\section{Results}

Our cohort consisted of 12687 patients with mechanical ocular trauma. Of these, 7546 (59.4\%) eyes had open globe ocular injuries and 5328 (41.9\%) had closed globe injuries. Among the open globe injury patients, $818(10.8 \%)$ had globe rupture and 417 (51\%) belonged to the pediatric age group ( $0-18$ years). The mean age of patients was $8.4 \pm 4.5$ years; besides, 283 were males $(67.9 \%)$ and 134 were females (32.1\%) (Table-1).

Of the 417 (51\%) who fell under the pediatric globe rupture group,130 (31.5\%) patients were under five years of age. Wooden stick and stone were the most common causative factors for the injury, which accounted for $49.3 \%$ and $16.9 \%$ of the cases, respectively. Play was the most common activity among the kids $(62.2 \%)$ that led to injuries either at home or in other places. In contrast, domestic (12.2\%) and professional (4.6\%) activities were the most frequent causative factors among teens and other 
children. Cornea was the most affected tissue in open globe injury and accounted for 331 (81.1\%) eyes (Table 2).

Out of the 106 (25.4\%) cases that required traumatic cataract removal during subsequent sessions, 39 (9.3\%) eyes necessitated vitrectomies to manage posterior segment comorbidities. Comparative studies between the pre- and post-treatment data indicated a significant difference in the visual outcome $(p=0.000)$ (Table-3).

Table 1: Age and Sex Distribution.

\begin{tabular}{|c|c|c|c|}
\hline \multirow{2}{*}{ Age Category } & \multicolumn{2}{|c|}{ Sex } & \multirow{2}{*}{ Total } \\
\cline { 2 - 4 } & F & 83 & 130 \\
\hline$<5$ & 47 & 200 & 287 \\
\hline$>5$ & 87 & 283 & 417 \\
\hline Total & 134 & M & 13 \\
\hline
\end{tabular}

Table 2: Wound Location.

\begin{tabular}{|c|c|c|}
\hline Wound Location & Frequency & Percent \\
\hline Cornea & 292 & 70 \\
\hline Cornea Sclera & 102 & 24.5 \\
\hline Sclera & 23 & 5.5 \\
\hline Total & 417 & 100 \\
\hline
\end{tabular}

Table 3: Comparative Study of Visual Outcome Before and After Surgery.

\begin{tabular}{|c|c|c|c|c|c|c|c|}
\hline \multirow{2}{*}{ Post Operative Vision } & \multicolumn{6}{|c|}{ Pre Operative Vision } & \multirow{2}{*}{ Total } \\
\hline & $<1 / 50$ & $1 / 60-3 / 60$ & $6 / 60-6 / 36$ & 6/24-6/18 & $6 / 12-6 / 9$ & $6 / 6-6 / 5$ & \\
\hline$<1 / 60$ & 178 & 1 & 0 & 10 & 0 & 1 & 190 \\
\hline $1 / 60-3 / 60$ & 22 & 4 & 0 & 0 & 1 & 0 & 27 \\
\hline $6 / 60-6 / 36$ & 12 & 6 & 2 & 3 & 0 & 0 & 23 \\
\hline $6 / 24-6 / 18$ & 52 & 4 & 3 & 37 & 6 & 0 & 102 \\
\hline $6 / 12-6 / 9$ & 29 & 10 & 2 & 10 & 5 & 0 & 56 \\
\hline $6 / 6-6 / 5$ & 10 & 0 & 2 & 3 & 2 & 2 & 19 \\
\hline Total & 303 & 25 & 9 & 63 & 14 & 3 & 417 \\
\hline
\end{tabular}

$\mathrm{P}=0.000$

Moreover, a comparative study between the children of amblyopiogenic age groups reflected a significant difference $(\mathrm{p}=$ 0.000) (Table 4).

It was observed that the vision regain was superior in the older age group. Of all the cases, 180 (43.2\%) required two surgeries, and

Table 4: Comparative Study of Visual Outcome According to Age.

\begin{tabular}{|c|c|c|c|}
\hline \multirow{2}{*}{ Post Operative Vision } & \multicolumn{2}{|c|}{ Age Category } & \multirow{2}{*}{ Total } \\
\cline { 2 - 4 } & 49 & 141 & 190 \\
\hline$<1 / 60$ & 6 & 21 & 27 \\
\hline $1 / 60-3 / 60$ & 6 & 17 & 23 \\
\hline $6 / 60-6 / 36$ & 64 & 38 & 102 \\
\hline $6 / 24-6 / 18$ & 2 & 54 & 56 \\
\hline $6 / 12-6 / 9$ & 6 & 16 & 19 \\
\hline $6 / 6-6 / 5$ & 130 & 287 & 417 \\
\hline Total & & & \\
\hline
\end{tabular}

$\mathrm{P}=0.000$

Table 5: Zone Wise Distribution.

\begin{tabular}{|c|c|c|}
\hline Zone & Number & Percent (\%) \\
\hline 1 & 340 & 81.5 \\
\hline 2 & 39 & 9.3 \\
\hline
\end{tabular}




\begin{tabular}{|c|c|c|}
\hline 3 & 38 & 9.2 \\
\hline Total & 417 & 100 \\
\hline
\end{tabular}

Table 6: Wound Shape.

\begin{tabular}{|c|c|c|}
\hline Shape & Frequency & Percent \\
\hline Irregular & 10 & 2.4 \\
\hline L Shaped & 6 & 1.1 \\
\hline Lenier & 380 & 91.1 \\
\hline Round & 5 & 1.2 \\
\hline Triradiate & 17 & 4.1 \\
\hline Total & 417 & 100 \\
\hline
\end{tabular}

The mean size of the wound was $6.18 \mathrm{~mm}$. On studying the influence, we did not find significant differences in the size or shape of the wound. ( $\mathrm{p}=0.56,0.95)$ (Table 6).

When we compared the outcome with the number of surgeries, we found significant influence ( $\mathrm{p}=0.008)$. Out of all, $18(4.3 \%)$ eyes presented with infection.

\section{Discussion}

Our cohort consisted of 417 (51\%) eyes amongst pediatric age group (0-18 years). No study has so far focused exclusively on the globe rupture subgroup of open globe injuries in pediatric patients. Most of the researchers have only broadly covered all the eye injuries in children [13-19]. Besides, several of the studies are concerned with small case series and are retrospective in nature [13-19]. Another key feature is that only a limited number of works have employed cross-sectional design [12]. Although prospective studies have been carried out in a few instances, they do not deal solely with globe rupture subcategory of open globe injuries [10,11,20-23]. The findings of our research contrast with some previously reported figures. For example, Khokhar et al. have documented that the prevalence of open globe injury is thrice as that of closed globe injury. Nonetheless, our research has indicated a narrower difference between the two, with closed globe and open globe injuries accounting for $41.9 \%$ and $59.4 \%$ of the cases, respectively [8].

According to our findings, which are also in agreement with those of other researchers such as Shah et al., the visual outcomes of pre- and post-amblyopia genic age groups differ significantly [11]. Even though Shah et al. have documented that the visual outcome is superior in case of pediatric closed globe injury patients, we have uncovered that a vision regains of $>6 / 24$ is achieved in $64.2 \%$ of the cases [20]. Investigations that are restricted to open globe trauma are scarce as most invariably cover overall trauma. As an exception, Canavan et al. have attempted a prospective study on trauma cases, but this study too is not limited to the pediatric age group [21]. The current study has stated the mean age of the patients to be 8.4 years. In the present work, the percentage of male patients was $67.9 \%$. Similarly, Serrano has reported $64.9 \%$ male patients, 10 and Sharifzadeh has documented a male-to-female ratio of 2.3:1 [22].
While Serrano has indicated that the proportion of blunt trauma is as low as 35\%, Liu has reported a whopping $71 \%$ of open globe injuries [13]. This contradiction may be attributed to the BETTS classification. According to Khokher et al., open globe injuries are thrice as prevalent as closed globe injuries, which may be due to the underreporting of the latter. In the present research, globe rupture constituted $10.8 \%$ of the eyes $[8,12,16]$. In the current study, we observed that while $67.3 \%$ of the eyes regained $>6 / 24$ visual acuity, $28 \%$ did not regain vision beyond $1 / 60$. Serrano has opined that most of the closed globe injuries do not cause severe visual loss, 8 which may due to the lack of severity of the injuries. Onyekonwu obtained a final visual outcome of $>6 / 18$ in $35.1 \%$ of the cases; but this figure is not specific for closed globe injuries [18]. Rapoport et al. noted only $30.5 \%$ open globe injuries in the general population [23]. According to Puodziuviene, while closed globe injuries were inferred to be higher in children aged 13-18 years, open globe injury was more common in the pre-school age group.18 Majority of the studies have reported that home is the most common location and play is the most common activity related to the injuries $[8,13,16,24]$.

The most probable mechanism of injury was blunt trauma, which accounted for $65 \%$ of the total cases reported by Mcewans [25]. Rohr et al. have asserted that the cornea is affected in $54 \%$ of the eyes in case of all types of injuries. However, the current study has identified that the cornea is affected in $81.1 \%$ of the eyes only with respect to open globe injuries [12]. We are not aware of any study that has so far examined the influence of size and shape of the wound on the visual outcome. We have also not come across any study that has documented the number of surgeries as well as the comparative differences in visual outcome. Studies have compared open and closed globe injuries [26] as well as overall outcome and outcome following blunt trauma [26]. Nonetheless, no specific study has covered globe rupture in children.

\section{Conclusion}

Globe rupture, which is a subgroup of open globe injury, is an important cause of severe vision loss. The condition is more common among males and youngsters. Even though treatment has a significant impact on the visual outcome, many children are facing serious vision loss even following treatment. 


\section{Acknowledgement}

- No financial support was received from any company or institution.

- This study has not been presented at any conference or meeting.

- The authors have no financial interest in any aspect of this study.

\section{Conflict of Interest}

None to declare.

\section{References}

1. Khatry SK, Lewis AE, Schein OD, Thapa MD, Pradhan EK, et al. (2004) The epidemiology of ocular trauma in rural Nepal. Br J Ophthalmol 88(4): 456-460.

2. Abraham DI, Vitale SI, West SI, Isseme I (1999) Epidemiology of eye injuries in rural Tanzania. Ophthalmic Epidemiol 6(2): 85-94.

3. D Virgil Alfaro, Eric P Jablon, Monica Rodriguez Fontal, Simon J Villalba, Robert E Morris, et al. (2005) Fishing-related ocular trauma. American Journal of Ophthalmology 139(3): 488-492.

4. Shah M, Shah S, Khandekar R (2008) Ocular injuries and visual status before and after Their management in the tribal areas of Western India: a historical cohort study. Grafes Arch Clin Exp Ophthalmol 246(2): 191197.

5. Agrawal R, Shah M, Mireskandari K, Yong GK (2013) Controversies in ocular trauma classification and management: review. Int Ophthalmol 33(4): 435-445.

6. Shah M, Shah S, Upadhyay P, Agrawal R (2013) Controversies in traumatic cataract classification and management: a review. Can J Ophthalmol 48(4): 251-258.

7. Kuhn F, Morris R, Witherspoon CD, Mester V (2004) The Birmingham Eye Trauma Terminology system (BETT). J Fr Ophtalmol 27(2): 206-210.

8. Khokhar S, Gupta S, Yogi R, Gogia V, Agarwal T (2014) Epidemiology and intermediate-term outcomes of open- and closed-globe injuries in traumatic childhood cataract. Eur J Ophthalmol 24(1): 124-130.

9. Serrano JC, Chalela P, Arias JD (2003) Epidemiology of childhood ocular trauma in a northeastern Colombian region. Arch Ophthalmol 121(10): 1439-1445.

10. Mehul A Shah, Shreya M Shah, Siddharth R Gosai, Satyam S Gupta, Raunaq R Khanna, et al. (2018) Comparative study of visual outcome between open- and closed-globe injuries following surgical treatment of traumatic cataract in children. European Journal of Ophthalmology 28(4): 406-411.

11. Mehul Shah, Shreya Shah, Ashit Shah, Jamini Pandya (2014) Geetopam Bardoloi Cataract How Important Is Age of Intervention. International Journal of Ophthalmology \& Eye Science 2: 302.
12. Puodziuviene E, Jokubauskiene G, Vieversytė M, Asselineau K (2018) A five-year retrospective study of the epidemiological characteristics and visual outcomes of pediatric ocular trauma. BMC Ophthalmol 18(1): 10.

13. Karaman K, Znaor L, Lakos V, Olujic I (2009) Epidemiology of pediatric eye injury in Split-Dalmatia County. Ophthalmic Res 42(4): 199-204.

14. Onyekonwu, GC, Chuka-Okosat CM (2008) Pattern and visual outcome of eye injuries in children at Abakaliki, Nigeria. West Afr J Med 27(3): 152-154.

15. Staffieri SE, Ruddle JB, Mackey DA (2010) Rock paper and scissors? Traumatic paediatric cataract in Victoria 1992-2006. Clin Exp Ophthalmol 38(3):237-241

16. Liu ML, Chang YS, Tseng SH, Cheng HC, Huang FC, et al. (2010) Major pediatric ocular trauma in Taiwan. J Pediatr Ophthalmol Strabismus 47(2): 88-95.

17. Ram J, Verma N, Gupta N, Chaudhary M (2012) Effect of penetrating and blunt ocular trauma on the outcome of traumatic cataract in children in northern India. J Trauma Acute Care Surg 73(3): 726-730.

18. Hoskin AK, Yardley AM, Hanman K, Lam G, Mackey DA (2016) Sportsrelated eye and adnexal injuries in the Western Australian paediatric population. Acta Ophthalmol 94(6): e407-e410.

19. Rohr JT, Santos PM, Ribeiro Dos Santos RC, Vieira CV, Fé LM, et al. (1992) Profile of pediatric eye trauma at Hospital de Base do Distrito Federal (HBDF), Brasilia, Brazil. Rev Assoc Med Bras 62(4): 324-329.

20. Canavan YM, O Flaherty MJ, Archer DB, Elwood JH (1980) A 10-year survey of eye injuries in Northern Ireland, 1967-76. Br J Ophthalmol 64(8): 618-625.

21. Sharifzadeh M, Rahmanikhah E, Nakhaee N (2013) Pattern of pediatric eye injuries in Tehran, Iran. Int Ophthalmol 33(3): 255-259.

22. Rapoport I, Romem M, Kinek M, Koval R, Teller J, et al. (1990) Eye injuries in children in Israel A nationwide collaborative study. Arch Ophthalmol 108(3): 376-379.

23. Singh S, Sharma B, Kumar K, Dubey A, Ahirwar K (2017) Epidemiology, clinical profile and factors, predicting final visual outcome of pediatric ocular trauma in a tertiary eye care center of Central India. Indian J Ophthalmol 65(11): 1192-1197.

24. MacEwen CJ, Baines PS, Desai P (1999) Eye injuries in children: the current picture. Br J Ophthalmol 83(8): 933-936.

25. Shah MA, Shah SM, Appleware AH, Patel KD, Rehman RM, et al. (2012) Visual outcome of traumatic cataract in pediatric age group. Eur Ophthalmol 22(6): 956-963.

26. Shah SM, Shah MA, Singh R, Rathod C, Khanna RA (2020) prospective cohort study on the epidemiology of ocular trauma associated with closed-globe injuries in pediatric age group. Indian J Ophthalmol 68(3): 500-503. 